\title{
BRAKE THERMAL EFFICIENCY ANALYSIS OF ENGINE FUELED KARANJA BIODIESEL USING TAGUCHI AND VALIDATION OF RESULTS
}

\author{
SATISH A. PATIL ${ }^{1 *} \&$ DR. R. R. ARAKERIMATH ${ }^{2}$ \\ ${ }^{1}$ Research Scholar, DYPatil Institute of Technology, Pune (MS), India \\ ${ }^{2}$ HOD, Mechanical Engineering, G H Raisoni College of Engineering and Management, Wagholi, Pune, India
}

\begin{abstract}
Biodiesel is synthesized from oils produced from vegetables and fats of animals which have properties like renewability, biodegradability, and as an efficient fuel. It is easily blended with petro diesel at any proportion. Engine noise-generating due to combustion in engines has a direct effect on engine performance. Some researchers are working on the engine using petro diesel and different blends of biodiesel for performance characteristics over the world. This paper covers the study of input parameters optimization for BTH of the engine. The tests have carried out at different combinations as per the orthogonal array obtained by the Taguchi method. This selection of orthogonal array has based on three parameters along with four levels of all individual parameters. The experimental output BTH values calculated have noted by the computerized engine setup. The results obtained by Minitab software have compared with results obtained by ANN and validated.

KEYWORDS: Transesterification, Biodiesel, Brake Thermal Efficiency
\end{abstract}

Received: Jun 08, 2020; Accepted: Jun 28, 2020; Published: Aug 17, 2020; Paper Id.: IJMPERDJUN2020780

\section{INTRODUCTION}

Use of diesel fuels in many different areas and have importance for the wealth of the country, there should be an alternative to diesel. An alternative to diesel fuel should be replicable, economical, as well as technically acceptable [1]. Biodiesel is produced by the transesterification process from renewable oils obtained from vegetable and animal fats using alcohol. Highly degradable, nontoxic, particulate matters, less carbon monoxide emission, unburned hydrocarbons are some important properties of biodiesel. Because of these properties, biodiesel has acquired international focus as a replacement for diesel [2]. Biodiesel may be used without modifications in existing compression ignition engines.

Totally 16 numbers of experiments have done as per array prepared by Minitab software using different inputs such as Biodiesel Blends, Load on Engine, and Compression Ratio. The output BTH of the engine with Karanja oil biodiesel blends for different sets of experiments obtained have noted. For the optimization of input parameters, the results have analyzed using the Taguchi method [3]. The main effective plot and interaction plots have plotted. The input parameter optimal conditions based on SN ratio value have searched for the maximum BTH of the engine $[4,5]$. The regression residual plot obtained by Minitab is compared with the regression residual plot by ANN [6]. The comparison of yield obtained by experimentation and ANN has also plotted together. There are very small differences between these values. 


\section{EXPERIMENTAL SETUP}

In the experimental setup, Kirloskar makes TV1, Variable CR, and 3.5 HP @ 1500 RPM. The engine' specifications are as below. The computerized system testbed has equipped with all required measuring instruments such as thermocouples, dynamometer, tachometer, flow meters, etc

Table 1: Engine Specifications

\begin{tabular}{|l|c|}
\hline \multicolumn{1}{|c|}{ Make } & Kirloskar \\
\hline No. of Cylinders & 1 \\
\hline No. of Strokes & 4 \\
\hline Type of Cooling & Water Cooling system \\
\hline Power Developing Capacity & $3.5 \mathrm{~kW} @ 1500 \mathrm{rpm}$. \\
\hline Range of C. R. & $12-18$ \\
\hline Stroke length & $110 \mathrm{~mm}$ \\
\hline Bore dia. & $87.5 \mathrm{~mm}$ \\
\hline Cylinder Volume & 661 \\
\hline
\end{tabular}

In this work, four different fuels have tested such as B0 (diesel 100\%), B15 (85\% diesel with15\%biodiesel), B20 ( $80 \%$ diesel with $20 \%$ biodiesel), and B25 (75\% diesel with $25 \%$ biodiesel)

\section{OPERATING PARAMETRIC CONDITIONS}

The effects of different parameters affecting the Transesterification Process have studied as follows.[6]

- Blends of Biodiesel

- $\quad$ Applied load on Engine

- Compression Ratio of engine

The operating parameter values have given below:

Table 2: Optimizing Parameter Ranges

\begin{tabular}{|c|c|c|}
\hline A: Blend & B: Load & C: Compression Ratio \\
\hline $\mathrm{A} 1=0$ & $\mathrm{~B} 1=0$ & $\mathrm{C} 1=16$ \\
\hline $\mathrm{A} 2=15$ & $\mathrm{~B} 2=4$ & $\mathrm{C} 2=17$ \\
\hline $\mathrm{A} 3=20$ & $\mathrm{~B} 3=7$ & $\mathrm{C} 3=17.5$ \\
\hline $\mathrm{A} 4=25$ & $\mathrm{~B} 4=10$ & $\mathrm{C} 4=18$ \\
\hline
\end{tabular}

\section{ANALYSIS OF BRAKE THERMAL EFFICIENCY BY TAGUCHI METHOD: [6]}

\section{Orthogonal Array}

The parametric design giving the number of conditions for all individual experiments in the orthogonal array. This orthogonal array selection has based on three parameters and four levels for the individual parameter as shown in above table number one.

Orthogonal array obtained by Minitab using operating parameters:

Summaryof Taguchi Design

Taguchi Array L $16\left(4^{\wedge} 3\right)$

No. of factors: 3 
No. of runs: 16

Columns of L16 (4^5) array: 123

Table 3: Sample Readings as per Obtained Taguchi Array

\begin{tabular}{|c|c|c|c|c|}
\hline Blend & Load & C.R. & BTH & SNR_BTH \\
\hline 0 & 0 & 16 & 17.49 & 24.8558 \\
\hline 15 & 4 & 16 & 22.33 & 26.97777 \\
\hline 15 & 7 & 18 & 22.52 & 27.05137 \\
\hline 20 & 0 & 17.5 & 15.16 & 23.61398 \\
\hline 25 & 4 & 17.5 & 18.34 & 25.26799 \\
\hline
\end{tabular}

In the above table 3, the yellowish row gives the higher value of the $\mathrm{SN}$ ratio which has indicated optimal input parameter values of engine for maximum BTH. For BTH the value of SN ratio, higher is better. The experimental maximum output value of BTH of the engine with input parameters blends B15, applied load $7 \mathrm{~kg}$, compression ratio18 has $22.52 \%$.

TAGUCHI ANALYSIS: BTH VERSUS BLEND, LOAD, C.R.

Model Summary

\begin{tabular}{|c|c|c|}
\hline S & R-Square value & R-Square. (adjusted) \\
\hline 0.6207 & $91.39 \%$ & $78.47 \%$ \\
\hline
\end{tabular}

\section{Regression Equation}

$\mathrm{BTH}=23.1-0.0872$ Blend +0.210 Load -0.216 C.R.

\section{Main Effective Plot for BTH}

The Plots obtained by Minitab software have shown below

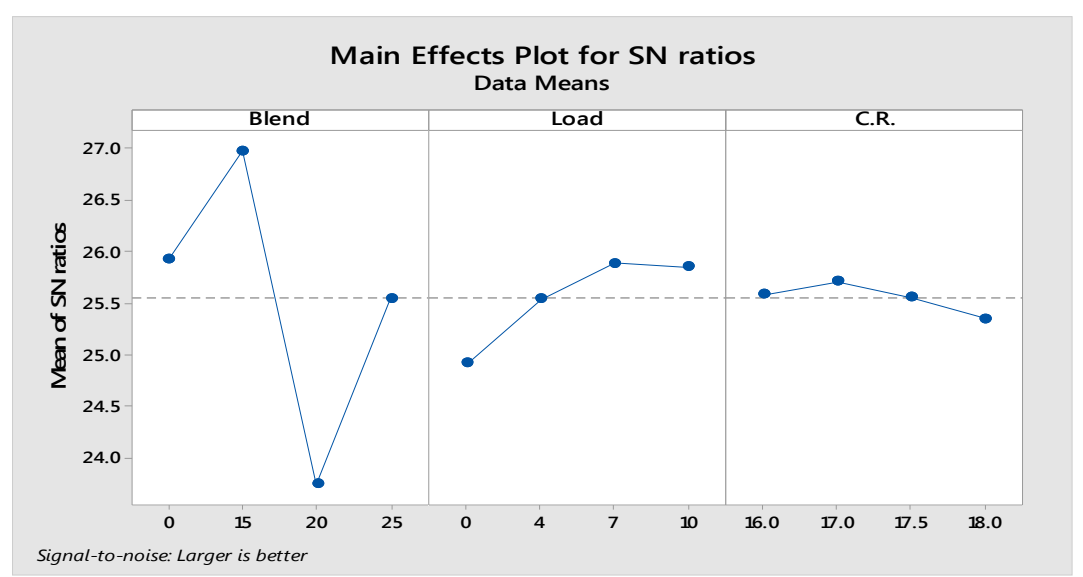

Figure 1: Main Effect Plot for BTH.

In the above main effect plots, $\mathrm{S} / \mathrm{N}$ ratios vs blend, and $\mathrm{S} / \mathrm{N}$ ratios vs load are comparatively steeper than $\mathrm{CR}$ plot. So, blend and load have affected more on the values of BTH. Therefore the effect of remaining one i.e. CR has neglected for further studies in the interaction plot. 


\section{INTERACTION PLOT FOR BTH: (6)}

Generally, the Taguchi method concrete on the main effects and that's important to test the other interactions. The variations of BTH of engine separately with the effect of blend and load simultaneously have shown in these interaction plots. From this interaction plot, Blend 15 having a larger value of SN ratio at $7 \mathrm{~kg}$ loads.

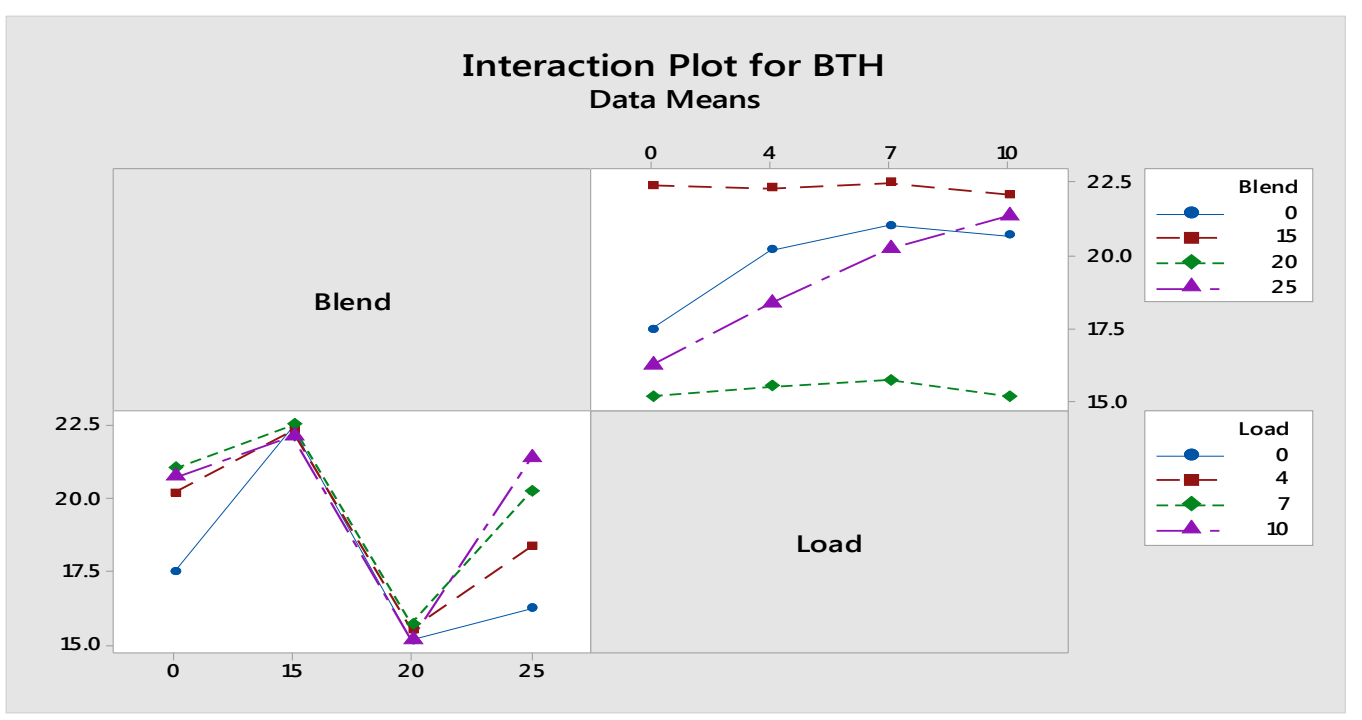

Figure 2: Interaction Plot for BTH.

\section{VALIDATION OF EXPERIMENTAL RESULTS USING TAGUCHI FOR BTH OF ENGINE BY ARTIFICIAL NEURAL NETWORK (ANN)}

Here the experimental results of BTH of the engine have validated by ANN (Artificial Neural Network).

\section{ANN Script for the Analysis Performed}

Script has written for obtaining the output by putting the values of input parameters

Table 3: ANN Script for the Analysis Performed

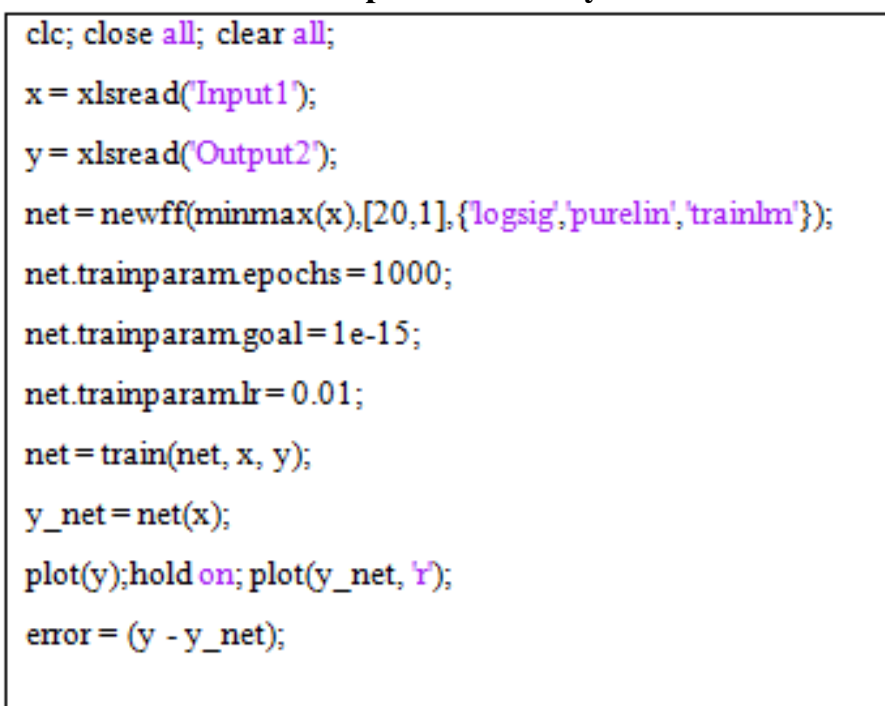




\section{Comparison of BTH of Engine Obtained by Experimentation and ANN}

Experimental values of BTH of engine and values calculated by ANN, error between them, and \% error are given in table 4.

Table 4: Sample Readings by Experiment and ANN

\begin{tabular}{|c|c|c|c|c|c|c|}
\hline Blend & Load & C.R. & BTH by Exp. & BTH by ANN & Error & Error \% \\
\hline 0 & 0 & 16 & 17.49 & 17.49 & 0.00 & $0.00 \%$ \\
\hline 15 & 4 & 16 & 22.33 & 22.33 & 0.00 & $0.00 \%$ \\
\hline 15 & 7 & 18 & 22.52 & 22.52 & 0.00 & $0.00 \%$ \\
\hline 20 & 10 & 17 & 15.15 & 15.15 & 0.00 & $0.00 \%$ \\
\hline 25 & 0 & 18 & 16.23 & 16.23 & 0.00 & $0.00 \%$ \\
\hline
\end{tabular}
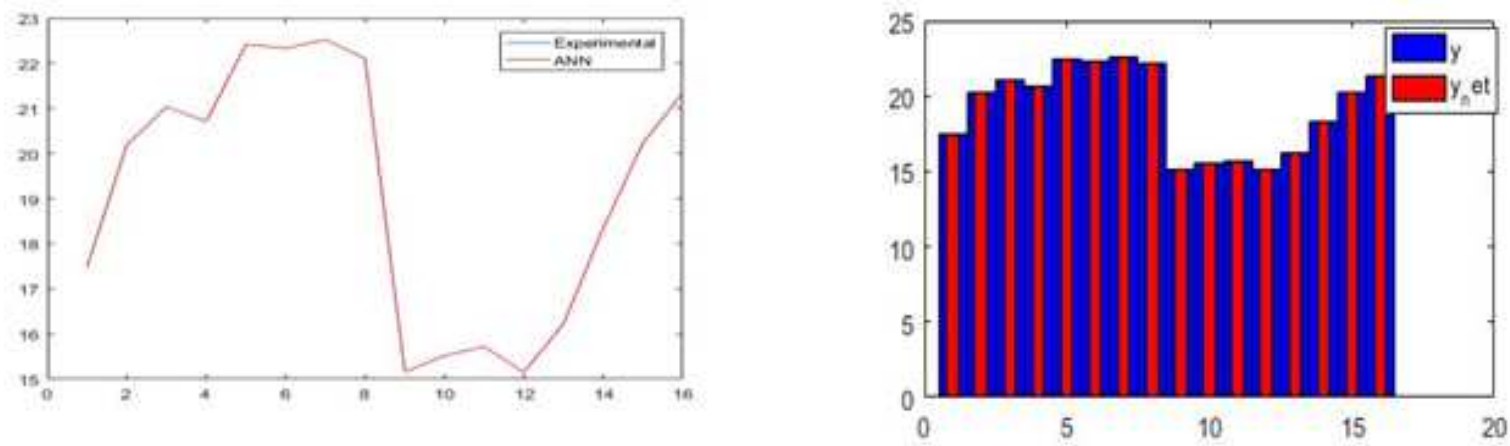

Figure 3: Comparison of BTH Obtained by Experimentation and ANN.

The comparative study of BTH of engine obtained by experimentation and ANN is as shown in Figure Fig. (3). There is a zero error in between these two values of BTH of the engine. In the table (3) the all values of BTH of engine obtained by experimentation and by ANN are given. There is no difference between these values and the \% error is also zero.

\section{Regression Plots: (6)}

The regression plots obtained by Minitab software and ANN have shown below. The comparison has made between these plots.
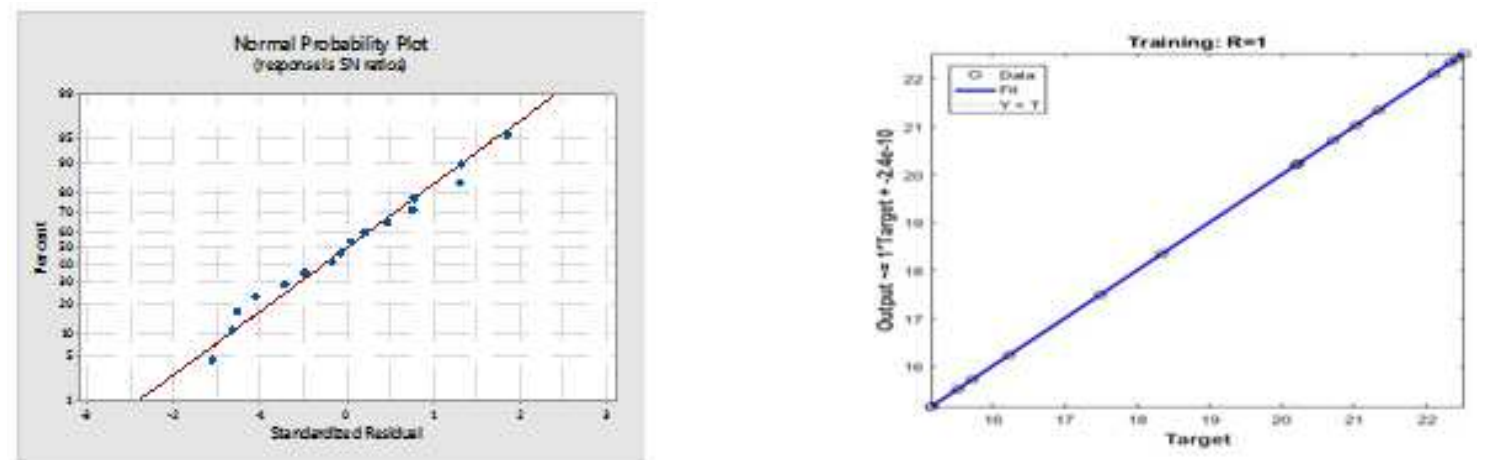

Figure 4: Comparison between Residual Plot for BTH by Minitaband by ANN.

There are very low residuals in the above both plots and all readings obtained are nearby or on the straight line. The R-square value for this regression has $91.39 \%$. 


\section{CONCLUSIONS}

This work has carried out for optimization of input parameters such as Biodiesel Blend, Load on Engine, and C R for output of BTH of the engine. The Taguchi method analysis using SNR base has performed for the optimization of input parameters. The results obtained by experimentation with Minitab are validated by ANN (Artificial Neural Network).The conclusions are as follows;

- The experimental output BTH of the engine has $22.52 \%$ with optimal input parameters blend B15, applied load 7 $\mathrm{kg}$, and compression ratio18.

- Interaction plots have shown the variation of BTH of the engine with the effect of blend and load simultaneously and also BTH of the engine has maximum value for blend 15 and load $7 \mathrm{~kg}$.

- $\quad$ The R square value obtained by analysis has $91.39 \%$, shows generated model has fitted to actual given data.

- There have no differences between values of BTH of engine obtained by experimentation and by ANN.

- The regression residuals plot obtained by Minitab has similar to ANN regression plot. Hence results have validated.

\section{REFERENCES}

1. Dipak Patil, Dr. Rachayya. Arakerimath. Performance characteristics and analysis of Jatropha oil in multi-cylinder turbocharge Compression Ignition Engine. International Journal of Engineering Research and Development ISSN: 2278067X, Volume 1, Issue 10 (June 2012), PP.50-55

2. Kumar, M. Naveen, Sriram. Venkatesh, and M. Manzoor Hussain. "Experimental investigation on influence of process parameters in selective laser sintering on roundness using taguchi medthod." International Journal of Mechanical and Production Engineering Research and Development 7.6 (2017): 45-52.

3. Avinash1, Kailash B Anwar2 \& Gowreesh,Optimization Of Diesel Engine Parameters with Blend ofPongamia Biodiesel and Diesel Using Taguchi Method,International Journal of Applied Engineering Research and Development (IJAERD)ISSN(P): 2250-1584; ISSN(E): 2278-9383Vol. 5, Issue 1, Feb 2015, 13-20

4. Matheswaran, M., and P. Suresh. "Study of EDM Process Parameters of Surface Roughness in Titanium Using Taguchi Method." International Journal of Mechanical and Production Engineering Research and Development (IJMPERD) 4.2 (2014): 63-68.

5. Dhruv V. Patel, Tushar M. Patel, Gaurav P Rathod, Parametric Optimization of Single Cylinder Diesel Engine for Jatropha Biodiesel and Diesel Blend For Brake Specific Fuel Consumption Using Taguchi Method, IOSR Journal Of Mechanical And Civil Engineering (IOSR-JMCE)E-ISSN: 2278-1684,P-ISSN: 2320-334X, Volume 12, Issue 2 Ver. VI (Mar - Apr. 2015), PP 66-72DOI: 10.9790/1684-12266672

6. Sivaraman, B. "Optimization of grinding parameters in austenitic stainless steel AISI 317L usingtaguchi method." International Journal of Mechanical and Production Engineering Research and Development 8.2 (2018): 10331038 .

7. P. Shanmughasundaram Palanisamy, Performance of Single Cylinder CI Engine Using Blends Of Rubber Seed BiodieselTaguchimethod U.P.B. Sci. Bull., Series D, Issn 1454-2358, Vol. 76, Iss. 4, 2014. 
8. Chavan S. B., Kumbhar R. R. and Sharma Y. C., Transesterification of Citrullus Colocynthis (Thumba) Oil Optimization for Biodiesel Production, Advances in Applied Science Research, 5(3):10-20, 2014.

9. Alavala, Chennakesava R. "Effect of Temperature, Strain Rate and Coefficient of Friction on Deep Drawing Process of 6061 Aluminum Alloy." International Journal of Mechanical Engineering 5.6 (2016): 11-24.

10. Satish A. Patil, R. R. Arakerimath, Optimization of Biodiesel Synthesis using Heterogeneous Catalyst (SiO2) from Karanja Oil by Taguchi Method. International Journal of Engineering and Advanced Technology (IJEAT). ISSN: 2249 - 8958, Volume-9 Issue-2, December 2019. 

